\title{
Ultrasonography in the refraction of aphakic infants
}

\author{
M. BELKIN, U. TIGHO, A. SUSAL, AND A. LEVINSON \\ Department of Ophthalmology, Hadassah University Hospital, Jerusalem, Israel
}

Modern management of congenital cataracts which interfere with vision consists of early removal of the cataract and correction of the refractive error by contact lenses or glasses (Parks and Hiles, I967; Von Noorden, Ryan, and Maumenee, I970).

Skiascopic postoperative refraction of aphakic infants cannot always be performed satisfactorily because the opening is sometimes small and irregular and no reflex can be seen. We, therefore, suggest that refractive error may be determined by calculation from ultrasonographic measurements.

\section{Material and methods}

Eleven eyes of seven infants who underwent cataract surgery during 1970 were examined. Details of the patients are given in Table I. The refractive error in each case was determined under general anaesthesia by the two techniques.

Table I Particulars of seven patients

\begin{tabular}{|c|c|c|c|}
\hline Case no. & Sex & Eye & $\begin{array}{l}\text { Age at operation } \\
(\text { mths })\end{array}$ \\
\hline I & $\mathbf{M}$ & Both & I 4 \\
\hline 2 & $\mathbf{M}$ & Right & 9 \\
\hline 3 & F & Right & 18 \\
\hline 4 & $F$ & Both & 4 \\
\hline 5 & $\mathbf{M}$ & Both & 36 \\
\hline 6 & $\mathbf{M}$ & Both & 6 \\
\hline 7 & $\mathbf{M}$ & Both & 5 \\
\hline
\end{tabular}

(I) The axial length of the eye was measured by Time-Amplitude Ultrasonography (TAU). The apparatus was built in our department (by A.S.)

The ultrasonic probe is a plain focused epoxy-encapsulated ceramic transducer. The free resonance of the lead-zirconate-titanate element in air is approximately $7.5 \mathrm{MH}_{\mathbf{z}}$. This provides a nearfield of $20 \mathrm{~mm}$. for ocular measurements, which is sufficient to ensure the beam has not spread excessively by the time it is reflected from the posterior wall complex. The diameter of the active surface of the ceramic element is $4 \mathrm{~mm}$., giving a beam divergence of approximately $3^{\circ}$. This transducer geometry fulfills the requirements for ultrasonic ocular biometry, since measurements between I 7 and $22 \mathrm{~mm}$. are generally involved.

The probe element is damped with a matching dispersive backing which limits ultrasonic ringing to 7 cycles for $30 \mathrm{db}$ pulse roll-off. The pulse repetition rate is $\mathrm{I}, 000$ pulses per second. A step function waveform with low driving impedance is used to excite the transducer. 
The receiver is a wide-band multiple integrated circuit amplifier with full-wave detection and echo processing. The display oscilloscope tube is $5^{\prime \prime}$ in diameter. A delayed expandable sweep control is provided. The length is read by comparing the echo position with display markers generated by an internal time-mark generator simultaneously displayed on the oscilloscope face.

From the axial length value thus obtained, the total dioptric power of the eye may be calculated, using the formula

$$
\mathrm{F}=\frac{n}{f} \times \mathrm{I}, \mathrm{ooo},
$$

when $\mathrm{F}$ is the total dioptric power of the eye, $n$ is the global refractive index, and $f$ is the anteroposterior diameter of the eye in millimetres (Emsley, 1952). The corneal curvature was measured by trial contact lens fitting technique, using lenses with a back optic diameter of $8 \mathrm{~mm}$. This procedure can measure the corneal radius of curvature within an error of $0.05 \mathrm{~mm}$. The refractive error was determined by subtracting the dioptric equivalent of the radius of curvature of the cornea measured by the trial contact lens fitting technique from the total dioptric power of the eye $(F)$.

(2) For control purposes, refraction was performed by skiascopy with a trial contact lens of the approximate dioptric power of the eye.

\section{Results (Table II)}

The ultrasonographic measurements of the antero-posterior diameter $(f)$ in the eleven eyes were between 20 and $22 \mathrm{~mm}$. By calculation from the formula

$$
\mathrm{F}=\frac{n}{f} \times \mathrm{I}, \mathrm{ooo}
$$

the total dioptric powers $(\mathrm{F})$ were found to be between $+60 \cdot 50$ and $+66 \cdot 75 \mathrm{D}$.

In ten of the eleven eyes, the radius of corneal curvature was between $7 \cdot 29$ and $7 \cdot 89$ $\mathrm{mm}$. (equivalent of $+46 \cdot 25$ and $+42 \cdot 75 \mathrm{D}$ respectively). In one eye the radius was $6 \cdot 36 \mathrm{~mm} .(+53 \mathrm{D})$.

\begin{tabular}{|c|c|c|c|c|c|c|}
\hline \multirow{2}{*}{$\begin{array}{l}\text { Case } \\
\text { no. }\end{array}$} & \multirow[t]{2}{*}{ Eye } & \multirow{2}{*}{$\begin{array}{l}\text { Ultrasonographically } \\
\text { measured antero- } \\
\text { posterior diameter } \\
(\text { to nearest } 0.5 \mathrm{~mm} .)\end{array}$} & \multirow{2}{*}{$\begin{array}{l}\text { Total dioptric } \\
\text { power calculated } \\
\text { from formula }\end{array}$} & \multicolumn{2}{|c|}{ Corneal curvature } & \multirow{2}{*}{$\begin{array}{l}\text { Refractive } \\
\text { error }\end{array}$} \\
\hline & & & & $m m$. & diopters & \\
\hline \multirow{2}{*}{1} & $\mathrm{R}$ & $22 \cdot 0$ & $+60 \cdot 50$ & $7 \cdot 45$ & $+4^{2 \cdot 25}$ & $+18 \cdot 25$ \\
\hline & $\mathrm{L}$ & $22 \cdot 0$ & $+60 \cdot 50$ & $7 \cdot 45$ & $+4^{2} \cdot 25$ & $+18 \cdot 25$ \\
\hline 2 & $\mathbf{R}$ & $21 \cdot 0$ & +63.50 & $7 \cdot 84$ & $+43 \cdot 00$ & $+20 \cdot 50$ \\
\hline 3 & $\mathbf{R}$ & $22 \cdot 0$ & $+60 \cdot 50$ & $7 \cdot 89$ & $+42 \cdot 75$ & $+17 \cdot 75$ \\
\hline \multirow{2}{*}{4} & $\mathrm{R}$ & $20 \cdot 5$ & $+65 \cdot 00$ & $7 \cdot 50$ & $+45 \cdot 00$ & $+20 \cdot 00$ \\
\hline & L & $20 \cdot 0$ & $+66 \cdot 75$ & $7 \cdot 58$ & $+44 \cdot 50$ & $+22 \cdot 25$ \\
\hline 5 & $\mathrm{R}$ & $22 \cdot 0$ & $+60 \cdot 50$ & $6 \cdot 36$ & $+53 \cdot 00$ & $+7 \cdot 50$ \\
\hline \multirow{2}{*}{6} & $\mathbf{R}$ & $20 \cdot 0$ & $+66 \cdot 75$ & $7 \cdot 71$ & $+43 \cdot 75$ & $+23 \cdot 00$ \\
\hline & $\mathrm{L}$ & $20 \cdot 0$ & $+66 \cdot 75$ & $7 \cdot 71$ & $+43 \cdot 75$ & $+23 \cdot 00$ \\
\hline \multirow{2}{*}{$\overline{7}$} & $\mathrm{R}$ & $22 \cdot 0$ & $+60 \cdot 50$ & $7 \cdot 29$ & $+46 \cdot 25$ & $+14 \cdot 25$ \\
\hline & $\mathbf{L}$ & $22 \cdot 0$ & $+60 \cdot 50$ & $7 \cdot 33$ & $+46 \cdot 00$ & $+14 \cdot 50$ \\
\hline
\end{tabular}

Table II Refractive error determined by ultrasonographic method 
By subtracting the corneal power trom the total dioptric power, the refractive error was determined. It was found to be between $+14 \cdot 25$ and $+23 \cdot 00 \mathrm{D}$ in ten eyes and $+7 \cdot 50 \mathrm{D}$ in a single eye.

Comparison between the refractive errors measured skiascopically and ultrasonographically (Table III) shows identical results in two eyes (Cases 2 and 5), a difference of half a diopter or less in four eyes, a difference of $0 \cdot 75$ to $1 \cdot 00$ diopters in three eyes, and a difference of $2 \cdot 25$ diopters in both eyes of Case I.

Table III Comparison of refractive errors as determined by ultrasonography and by skiascopy

\begin{tabular}{|c|c|c|c|}
\hline \multirow[t]{2}{*}{$\begin{array}{l}\text { Case } \\
\text { no. }\end{array}$} & \multirow[t]{2}{*}{ Eye } & \multicolumn{2}{|c|}{$\begin{array}{l}\text { Refractive error (to nearest } 0 \cdot 25 D) \\
\text { determined by }\end{array}$} \\
\hline & & Ultrasonography & Skiascopy \\
\hline \multirow{2}{*}{ I } & $\mathrm{R}$ & $+18 \cdot 25$ & $+16 \cdot 00$ \\
\hline & $\mathrm{L}$ & $+18 \cdot 25$ & $+16 \cdot 00$ \\
\hline 2 & $\mathrm{R}$ & $+20 \cdot 50$ & $+20 \cdot 50$ \\
\hline 3 & $\mathrm{R}$ & $+17 \cdot 75$ & $+18 \cdot 00$ \\
\hline \multirow{2}{*}{4} & $\mathrm{R}$ & $+20 \cdot 00$ & $+20 \cdot 50$ \\
\hline & $\mathrm{L}$ & $+22 \cdot 25$ & $+21 \cdot 50$ \\
\hline 5 & $\mathrm{R}$ & $+7 \cdot 50$ & $+7 \cdot 50$ \\
\hline \multirow{2}{*}{6} & $\mathrm{R}$ & $+23 \cdot 00$ & $+24 \cdot 00$ \\
\hline & $\mathrm{L}$ & $+23 \cdot 00$ & $+24 \cdot 00$ \\
\hline \multirow{2}{*}{7} & $\mathrm{R}$ & $+14 \cdot 25$ & $+14 \cdot 00$ \\
\hline & $\mathrm{L}$ & $+14 \cdot 50$ & $+14 \cdot 00$ \\
\hline
\end{tabular}

The Wilcoxon matched-pairs signed ranks test was performed on this data; it established that the differences between the value obtained by the two techniques are not statistically significant ( $\alpha=0 \cdot 0 \mathrm{I} ; n=9 ; \mathrm{T}=\mathrm{I} 8$ ).

\section{Discussion}

Skiascopic determination of the refractive error of aphakic eyes of infants is sometimes difficult or impossible because of small or irregular openings of the posterior lens capsule in the pupillary area. Accurate measurement of the axial length of the eyes enables us to overcome this difficulty.

Since the aphakic eye is a simple optical system in which the cornea is the only refractive surface, it is possible to calculate its total refractive power using the formula, and by subtracting the corneal refractive power from it to determine the necessary prescription.

Since contact lenses create a perfect lacrimo-corneal spherical surface, thus eliminating any astigmatic crror, this type of error does not interfere with the calculation and prescription of contact lenses. 
The use of TAU for ocular biometry is long established (Mundt and Hughes, I 956 ; Franken, I962; Giglio, 1969) in spite of its possible errors (Kimura, Yamazaki,ŏ Nakajima, Hayashi, and Nagata, 1969). The errors are mainly due to the presence $\Rightarrow$ of the lens, in which the velocity of sound is different from that in the rest of the ocular $\stackrel{5}{5}$ components (Oksala and Varonen, 1965). This obstacle does not exist, of course, in aphakic eyes. It was previously suggested for aphakic refraction (Elenius and Sopanen, I963), but is not generally used.

A comparison of the refractive error as calculated from corneal curvature and axial@ length measurements with that obtained by skiascopic refraction shows no significant $\vec{o}$ differences.

This simple method therefore seems to be adequate for general use in prescribing contact lenses or determining the equivalent spherical measurement in aphakic eyes, especially응 in infants and children.

\section{Summary}

A method of aphakic refraction, using ultrasonographic axial length measurement ando contact lens corneal curvature determination, is presented. No significant difference was found when this method was compared with skiascopy in refracting eleven eyes of aphakic infants.

The authors wish to express their appreciation to Mr. George Nissel of London for his contribution towards this research.

\section{References}

elenius, v., and SOPANEN, v. (1963) Acta ophthal. (Kbh.), 41, $7 \mathrm{I}$

EMSLEY, H. H. (1952) "Visual Optics", 5th ed., vol I, p. 36o. Hatton, London

FRANKEN, S. (1962) Ophthalmologica (Basel), $\mathbf{1 4 3}, 82$

GIGLIO, E. J. (I969) In "Ophthalmic Ultrasound", Proc. IV int. Congr. Ultrasonography in

Ophthalmology, Philadelphia, ed. K. A. Gitter, A. H. Keeney, L. K. Sarin, and D. Meyer,

pp. I 22-133. Mosby, St. Louis

KimURA, T., YAMAZAKI, M., NAKAJIMA, A., HAYAShi, c., and NAGATA, y. (ig69) Idem, pp. igo-200

MUNDT, G. H., JR., and hUGhes, W. F., JR. (1956) Amer. F. Ophthal., 41, 488

oksala, A., and varonen, E. (1965) Acta ophthal. (Kbh.), 43, 260

PARKs, м. м., and hiles, D. A. (1967) Amer. F. Ophthal., 63, io

von Noorden, G. K., Ryan, s. J., and maumenee, A. E. (1970) Trans. Amer. Acad. Ophthal. Otolaryng.,

74, $35^{2}$ 